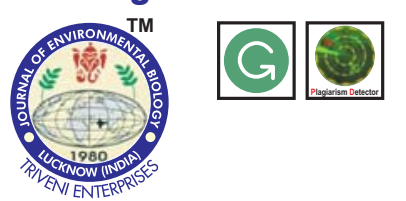

\title{
Bacterial diversity and antibiotic resistance in a wetland of Lakhimpur- Kheri, Uttar Pradesh, India
}

Authors Info

Rupesh Kumar Mishra', Dev

Kumar Verma', Ravindra', Manoj

Kumar Yadav', Pravata Kumar

Pradhan $^{1 *}$, T. Raja Swaminathan ${ }^{2}$ and Neeraj Sood ${ }^{1}$

${ }^{1}$ Fish Health Management Division, ICAR-National Bureau of Fish Genetic Resources, Lucknow-226 002, India

${ }^{2}$ Peninsular and Marine Fish Genetic Resources Division, NBFGR, CMFRI Campus, Kochi682018 , India

${ }^{*}$ Corresponding Author Email : pradhanpk1@gmail.com

Key words

Antibiotic sensitivity, Bactrial isolates, $16 \mathrm{~S}$ rDNA sequencing, Multiple antibiotic resistance, Phylotypes

Publication Info

Paper received : 10.07.2015

Revised received : 21.11 .2015

Re-revised received : 17.05 .2016

Accepted : 26.07.2016
Abstract

Aim : Knowledge about the structure of microbial community is essential to assess the risks of exposure of farmed fish to pathogens and studying the antibiotic resistance. The present study was carried out to assess the bacterial diversity in a freshwater ecosystem.

Methodology: In the present study, microbial composition of a wetland in Lakhimpur-Kheri (N $27^{\circ} 90.25^{\prime}$ and $\mathrm{E} 80^{\circ} 79.80^{\prime}$ ), Uttar Pradesh was assesesed employing amplified rDNA restriction analysis (ARDRA), using Haelll enzyme as well as $16 \mathrm{~S}$ rDNA gene sequencing. Furthermore, antibiotic resistance of the bacterial isolates was determined on the basis of multiple antibiotic resistance (MAR) index.

Results : A total of one hundred and thirty five bacteria were isolated and the restriction analysis of amplified 16S rDNA gene of the above isolates, using Haelll enzyme, indicated that isolated bacteria belonged to 33 single member phylotypes. Molecular characterization of the isolates revealed that these phylotypes belonged to 20 genera under 6 classes viz., Gammaproteobacteria (72.59\%), Betaproteobacteria (4.44\%), Flavobacteria (9.63\%), Bacilli (7.41\%) Actinobacteria (3.70\%) and Sphingobacteria $(2.22 \%)$. In the present study, four species i.e. Sphingobacterium kitahiroshimense, Yersinia nurmii, Pseudomonas koreensis and Vogesella alkaliphila have been reported for the first time from a wetland. The antibiotic sensitivity test indicated that most of the isolates were sensitive to norfloxacin followed by ofloxacin, whereas, majority of these bacteria were resistant to penicillin $\mathrm{G}$ followed by polymyxin B. Moreover, MAR indexing revealed that amongst the 33 single member phylotypes, 17 were multiple antibiotic resistant.

Interpretation : The bacterial diversity analysis of the wetland indicated bacterial population of aquatic, soil, animal and plant origin. Moreover, the study indicated that wetland can be a reservoir for multidrug resistant bacteria even when there is no application of antibiotics for aquaculture purposes. It can be assumed that the occurrence of antibiotic resistance and MAR among bacteria isolated from wetland could be due to flow of runoff from mainland. These results would help in strengthening our knowledge of bacterial ecology of the wetland ecosystem.

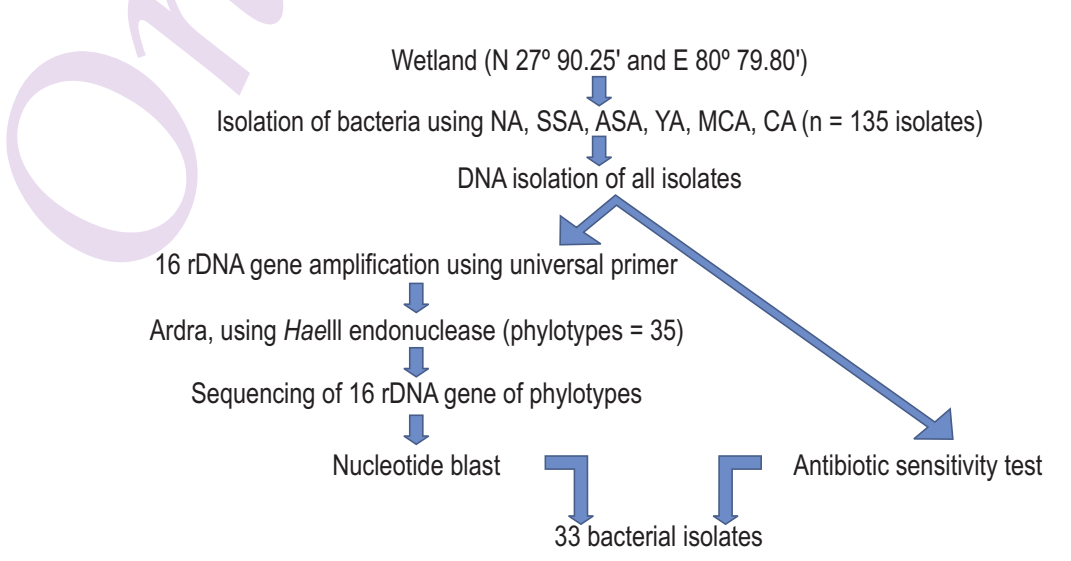




\section{Introduction}

Over the last two decades, Indian aquaculture has shown phenomenal growth of 6-7\% per year with carps in freshwater and shrimps in brackishwater as major contributors. Although aquaculture has been identified as sunrise sector for meeting the growing demand of fish in years to come, several disease outbreaks are posing severe threat to the growth of this sector. Irrespective of type of aquaculture and species, bacterial diseases rank number one amongst the fish diseases and pose a significant challenge (Bondad-Reantaso et al., 2005).

Microbial communities are closely associated with plants and animals, and play an important role in making necessary nutrients, metals and vitamins available to their hosts. To understand the role of microbes in the ecosystems, it is essential to know the structure of microbial community, which can not only provide an insight into large-scale ecological processes in a freshwater environment but also help in assessing the risk of exposure of farmed fish to pathogens (Zeng et al., 2010). To characterize microbial ecology, routinely employed culture techniques involve isolation and characterization of microorganisms using growth media which can be nonselective or selective. Nonselective media allow a wide variety of bacteria to grow, whereas, selective media allow only certain organisms to grow because they have specific inhibitors added to the media. However, most of these techniques are manual and require significant effort and time to be performed. To overcome these shortcomings, during the recent times, a large number of molecular techniques especially $16 \mathrm{~S}$ rDNA sequencing and amplified rDNA restriction analysis (ARDRA) have been developed to explore the diversity of microbial communities (Baik et al., 2008). These techniques are rapid and allow accurate identification of bacteria up to the species level (Urakawa et al., 1999; Yoon et al., 2003).

The development of antibiotic resistance among pathogens has been recognized as a serious global health threat (Nguyen et al., 2014). There are many reports that have established a link between antibiotic use in food producing animals and emergence of antibiotic resistance in bacteria, and transfer of these resistant organisms to humans (or their resistance genes to human pathogens) via food chain (Barton, 2000; Stobberingh and van den Bogaard, 2000; Angulo et al., 2004; Akinbowale et al., 2007). Considering apparent increase in the occurrence of antibiotic resistance among bacteria during the past years, and its possible implications for public health, many countries have initiated intensified surveillance for bacterial drug resistance (Schmidt et al., 2000; Ash et al., 2002; Lim et al., 2013; Nguyen et al., 2014). However, there is meagre information regarding bacterial diversity and antibiotic resistance associated with freshwater ecosystem in the country. Therefore, in the present study, a preliminary assessment of the microbial composition in a freshwater environment was carried out to examine antibiotic resistance of the isolated bacteria. Amplified rDNA restriction analysis (ARDRA) and $16 \mathrm{~S}$ rDNA sequencing were used for rapid and accurate identification of bacteria up to species level.

\section{Materials and Methods}

Sample collection : A wetland (N $27^{\circ} 90.25^{\prime}$ and E 80 $79.80^{\prime}$ ) located in Lakhimpur-Kheri district of Uttar Pradesh, India, with extensive aquaculture practice and no evidence on the use of antibiotics, was selected for the present study. The area of water body was approximately 17 ha with average water depth of $1.5 \mathrm{~m}$. Sampling was carried out in the month of January (winter season) when there was a maximum likelihood of disease occurrence. Water samples were collected by submerging sterile glass bottles $(250 \mathrm{ml})$ at six representative areas of water body and transported aseptically to laboratory on ice for further processing. Furthermore, water quality parameters viz. dissolved oxygen, temperature and $\mathrm{pH}$ were also recorded by a Universal Pocket Meter (Thermo Scientific, Waltham, Massachusetts, United States).

Bacteriological analysis : All the six water samples were pooled in a single bottle aseptically and one $\mathrm{ml}$ of pooled sample was diluted ten-fold, up to $10^{-5}$ in $0.85 \%$ normal saline solution. Aliquots of $0.1 \mathrm{ml}$ of serial dilutions were inoculated in duplicate on nutrient agar, as well as selective and differential media viz., Aeromonas specific agar, Salmonella shigella agar, Yersinia agar, MacConkey agar and Cytophaga agar (Hi-Media, India), using traditional spread plate method. The samples were processed aseptically and plated within $5 \mathrm{hrs}$ of collection. All the inoculated plates were incubated at $25^{\circ} \mathrm{C}$ for $48 \mathrm{hrs}$. The colony types differing in terms of size, color, shape and morphology on different media were selected for further analysis. For characterization, all the purified isolates were stored at $-80^{\circ} \mathrm{C}$ in nutrient broth supplemented with $15 \%$ glycerol. Representative purified isolates were subjected to Gram staining, motility, oxidase and catalase tests. The isolates were also subjected to biochemical tests employing Bacterial identification kit $\mathrm{KB} 003 \mathrm{Hi} 25^{\mathrm{TM}}$ (HiMedia, India).

Bacterial genomic DNA extraction and 16S rDNA PCR amplification : DNA extraction was performed by CTAB method (Wilson, 1994). A single colony of purified isolates was inoculated in $2 \mathrm{ml}$ nutrient broth, incubated overnight at $25^{\circ} \mathrm{C}$, and the culture was used for DNA extraction. DNA was suspended in $50 \mu \mathrm{l}$ of TE buffer $(\mathrm{pH} 7.8)$ and stored at $-20^{\circ} \mathrm{C}$ for further study. The $16 \mathrm{~S}$ rDNA gene was amplified using universal primers and PCR conditions as per Weisburg et al. (1991). The PCR products were visualized on $1.2 \%$ agarose gel. The PCR products were excised and purified using QIAquick gel extraction kit (Qiagen, Venlo, Netherlands).

Amplified rDNA restriction analysis (ARDRA) : About $10 \mu \mathrm{l}$ $(200 \mathrm{ng})$ of amplified 16S rDNA gene from different isolates was 
digested using Haelll restriction enzyme (Fermentas, Vilnius, Lithuania) as per manufacturer's instructions. The resulting fragments were resolved in $3 \%$ agarose gels which were stained with ethidium bromide and photographed with UV transilluminator (Bio-Rad, Hercules, California, United States). As per gel analysis, presence or absence of restriction site were either indicated as 1 or 0 . These data were then used to generate a dendrogram (NTSYSpc 2.02e) to analyze the relationship among the isolates. Cluster analysis was performed on similarity matrix with sequential, agglomerative, hierarchical and nested clustering methods (SAHN) using unweighted pair-group method with arithmetic mean (UPGMA) and a dendrogram of the outcome was generated.

Sequencing and data analysis : The amplified and purified $16 S$ rDNA gene products of representative isolates from each identified group in ARDRA were sequenced using forward primer $27 \mathrm{~F}$, from a commercial sequencing facility (Xcelris Bio-lab,
Hyderabad, India). Partial 16S rDNA sequences of all the bacterial isolates were submitted to NCBI GenBank nucleotide sequence database (Table 1). The homology of their 16S rDNA gene sequences was analyzed in the EzTaxon server (http://www.ezbiocloud.net/eztaxon) (Kim et al., 2012). The sequences were aligned independently using CLUSTALX (Thompson et al., 1997) and construction of phylogenetic tree by neighbor-joining method was carried out using MEGA6 program (Tamura et al., 2013). The topology of phylogenetic tree was evaluated by bootstrap re-sampling method with 1000 replicates.

Antimicrobial sensitivity assay : Isolates stored at $-80^{\circ} \mathrm{C}$ were streaked on nutrient agar plates and processed for antimicrobial sensitivity test using the disc diffusion method (Finegold and Martin, 1982). Twelve antimicrobial agents (Himedia, India) were selected as representative of different classes of antibiotics: Penicillin-G, Gentamicin, Norfloxacin, Tobramycin, Streptomycin, Kanamycin, Tetracycline, Chloramphenicol,

Table 1 : Total number of isolates $(n)$ from wetland and similarity values of $16 \mathrm{~S}$ rDNAgene sequences of 33 single member phylotype of bacterial isolates, showing similarity to nearest relative and taxonomic class of the strains

\begin{tabular}{|c|c|c|c|c|c|}
\hline Strain I.D. & $\begin{array}{l}\text { Medium for } \\
\text { primary isolation }\end{array}$ & $\begin{array}{l}\text { GenBank } \\
\text { accession no. }\end{array}$ & $\begin{array}{l}\text { Closest relative species in theEz-Taxon } \\
\text { database and Ez-Taxon accession no. }\end{array}$ & $\begin{array}{l}\text { Similarit } \\
(\%)\end{array}$ & Class \\
\hline FHMDC2F3-1 (n=5) & SSA, NA & KM069460.1 & Citrobacterfreundii(ANAV01000046) & 99.72 & Gammaproteobacteria \\
\hline FHMDA1P1-2 (n=12) & SSA, NA & KM069461.1 & Aeromonas punctata subsp. punctata (X60408) & 100 & Gammaproteobacteria \\
\hline FHMDA1A1-4 $(n=5)$ & YA, NA, MCA & KM069462.1 & Aeromonas allosaccharophila (S39232) & 99.75 & Gammaproteobacteria \\
\hline FHMDC3P1-12 (n=2) & NA & KM069463.1 & Curtobacterium plantarum (JN175348) & 99.83 & Gammaproteobacteria \\
\hline FHMDE1B1-19 $(n=1)$ & ASA & KJ997754.1 & Erwinia billingiae (AM055711) & 98.86 & Gammaproteobacteria \\
\hline FHMDP2A1-23 (n=2) & YA, NA & KJ997757.1 & Providencia alcalifaciens (ABXW01000071) & 99.55 & Gammaproteobacteria \\
\hline FHMDA1C1-24 (n=8) & YA, NA, MCA & KM069464.1 & Aeromonas punctata subsp. caviae (X74674) & 100 & Gammaproteobacteria \\
\hline FHMDS1F1-28 (n=2) & MCA & KJ997759.1 & Shigella flexneri(X96963) & 99.68 & Gammaproteobacteria \\
\hline FHMDA1V1-32 $(n=6)$ & $C A, N A, M C A$ & KJ997746.1 & Aeromonas veronii(X60414) & 100 & Gammaproteobacteria \\
\hline FHMDA301-34 (n=5) & NA, MCA & KJ997748.1 & Acinetobacteroryzae (GU954428) & 99.03 & Gammaproteobacteria \\
\hline FHMDE2C1-41 $(n=4)$ & MCA, NA & KJ997755.1 & Enterobacter cloacae subsp. dissolvens (Z96079) & 100 & Gammaproteobacteria \\
\hline FHMDP1K1-42 (n=5) & SSA, NA, MCA & KJ997756.1 & Pseudomonas koreensis (AF468452) & 99.63 & Gammaproteobacteria \\
\hline FHMDR1A1-48 (n=2) & $\mathrm{NA}, \mathrm{MCA}$ & KJ997758.1 & Rahnella aquatilis (CP003244) & 98.51 & Gammaproteobacteria \\
\hline FHMDE2M1-55 (n=2) & ASA, NA & KM06 & Enterobactermori(GL890774) & 99.02 & Gammaproteobacteria \\
\hline FHMDP1C1-59 (n=3) & $\mathrm{CA}, \mathrm{NA}$ & KM069469.1 & Pseudomonas chengduensis (EU307111) & 99.40 & Gammaproteobacteria \\
\hline FHMDY1N4-60 ( $n=6)$ & NA, NA & KM069470.1 & Yersinia nurmii (FJ717338) & 98.59 & Gammaproteobacteria \\
\hline FHMDA1AUS1-66 (3) & NA, MCA & KM069471.1 & Aeromonas australiensis (HE611955) & 99.79 & Gammaproteobacteria \\
\hline FHMDR2C1-72 $(n=2)$ & $\mathrm{CA}, \mathrm{NA}$ & 73.1 & Rheinheimera chironomi (DQ298025) & 99.79 & Gammaproteobacteria \\
\hline FHMDP1P1-86 $(n=6)$ & ASA, NA, MCA & KM01 & Pseudomonas psychrophila (AB041885) & 100 & Gammaproteobacteria \\
\hline FHMDA1M1-87 (n=4) & ASA, NA, MCA & KM069477.1 & Aeromonas media (X74679) & 100 & Gammaproteobacteria \\
\hline FHMDE2L1-103(n=1) & SSA & KM014555.1 & Enterobacterludwigii(AJ853891) & 99.89 & Gammaproteobacteria \\
\hline FHMDK1I1-113 (n=2) & SSA, NA & KM014556.1 & Kluyvera intermedia(AF310217) & 100 & Gammaproteobacteria \\
\hline FHMDA1MOL1-114(n=10) & SSA, NA, MCA & KM069478.1 & Aeromonas molluscorum (AY532690) & 99.65 & Gammaproteobacteria \\
\hline FHMDV1A1-107 $(n=5)$ & $\mathrm{NA}, \mathrm{NA}, \mathrm{MCA}$ & KM014558.1 & Vogesella alkaliphila (HE819389) & 100 & Betaproteobacteria \\
\hline FHMDJ1L1-46 (n=1) & NA & KM069465.1 & Janthinobacterium lividum (Y08846) & 99.69 & Betaproteobacteria \\
\hline FHMDA2N1-29 (n=3) & $\mathrm{CA}, \mathrm{NA}$ & KJ997747.1 & Arthrobacternicotianae (X80739) & 97.87 & Actinobacteria \\
\hline FHMDM1L1-80 (n=2) & $\mathrm{CA}, \mathrm{NA}$ & KM069476.1 & Micrococcus luteus (CP001628) & 100 & Actinobacteria \\
\hline FHMDC1N1-33 (n=7) & NA, CA, MCA & KJ997751.1 & Chryseobacterium nakagawai (JX100822) & 98.27 & Flavobacteria \\
\hline FHMDC1S1-47 (n=2) & $\mathrm{NA}, \mathrm{CA}$ & KM069466.1 & Chryseobacterium scophthalmum (AJ271009) & 100 & Flavobacteria \\
\hline FHMDC1H1-78 $(n=4)$ & CA, NA, MCA & KJ997750.1 & Chryseobacterium haifense (EF204450) & 97.32 & Flavobacteria \\
\hline FHMDB1M1-69 $(n=6)$ & CA, NA, MCA & KJ997749.1 & Bacillus megaterium (D16273) & 99.65 & Bacilli \\
\hline FHMDB2C1-98 $(n=4)$ & CA, NA, MCA & KR363106.1 & Bacillus cereus (AE016877) & 100 & Bacilli \\
\hline FHMDS2K1-74 (n=3) & NA, MCA & KM069475.1 & Sphingobacterium kitahiroshimense (AB361248) & 99.80 & Sphingobacteria \\
\hline
\end{tabular}




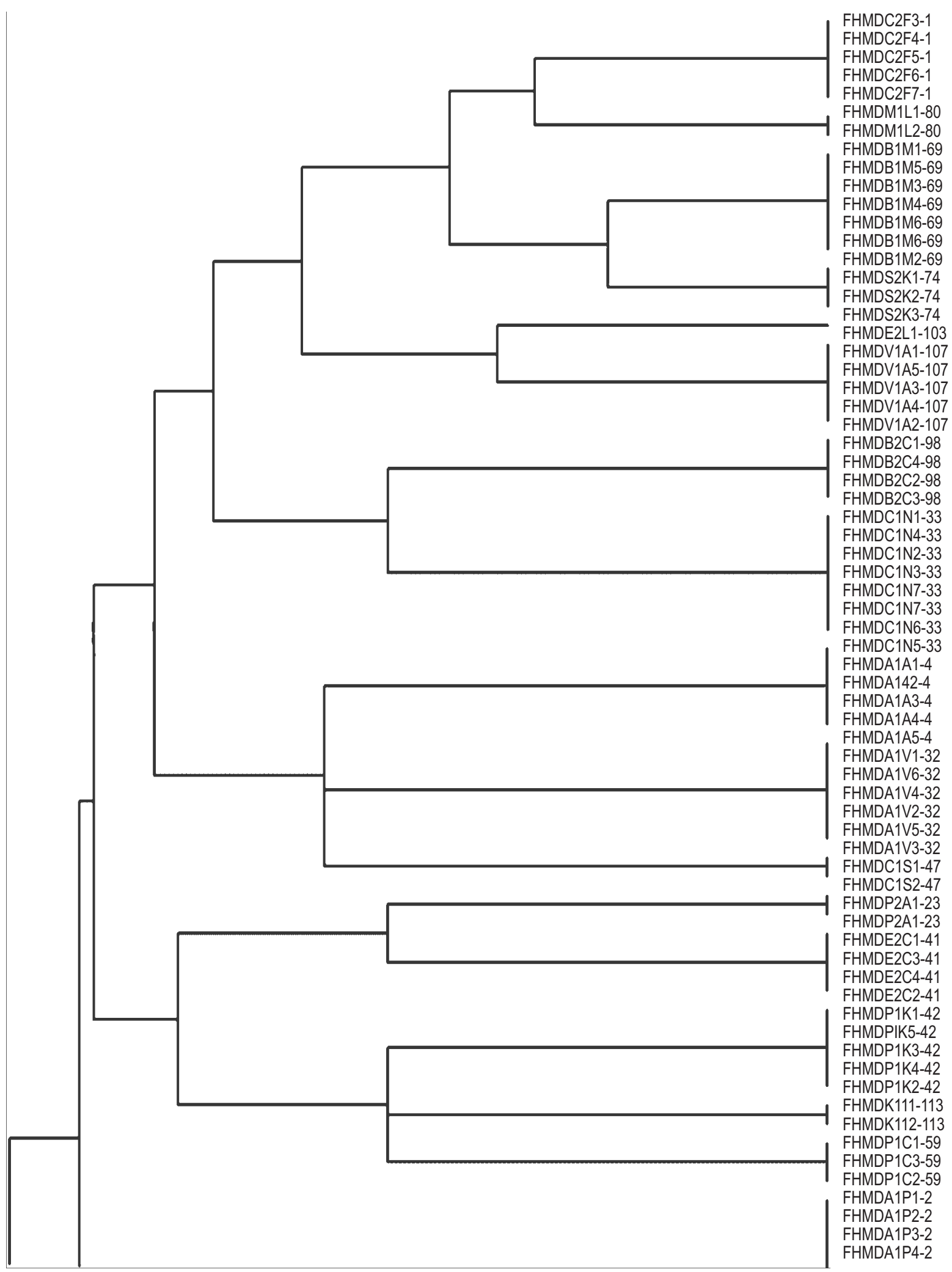




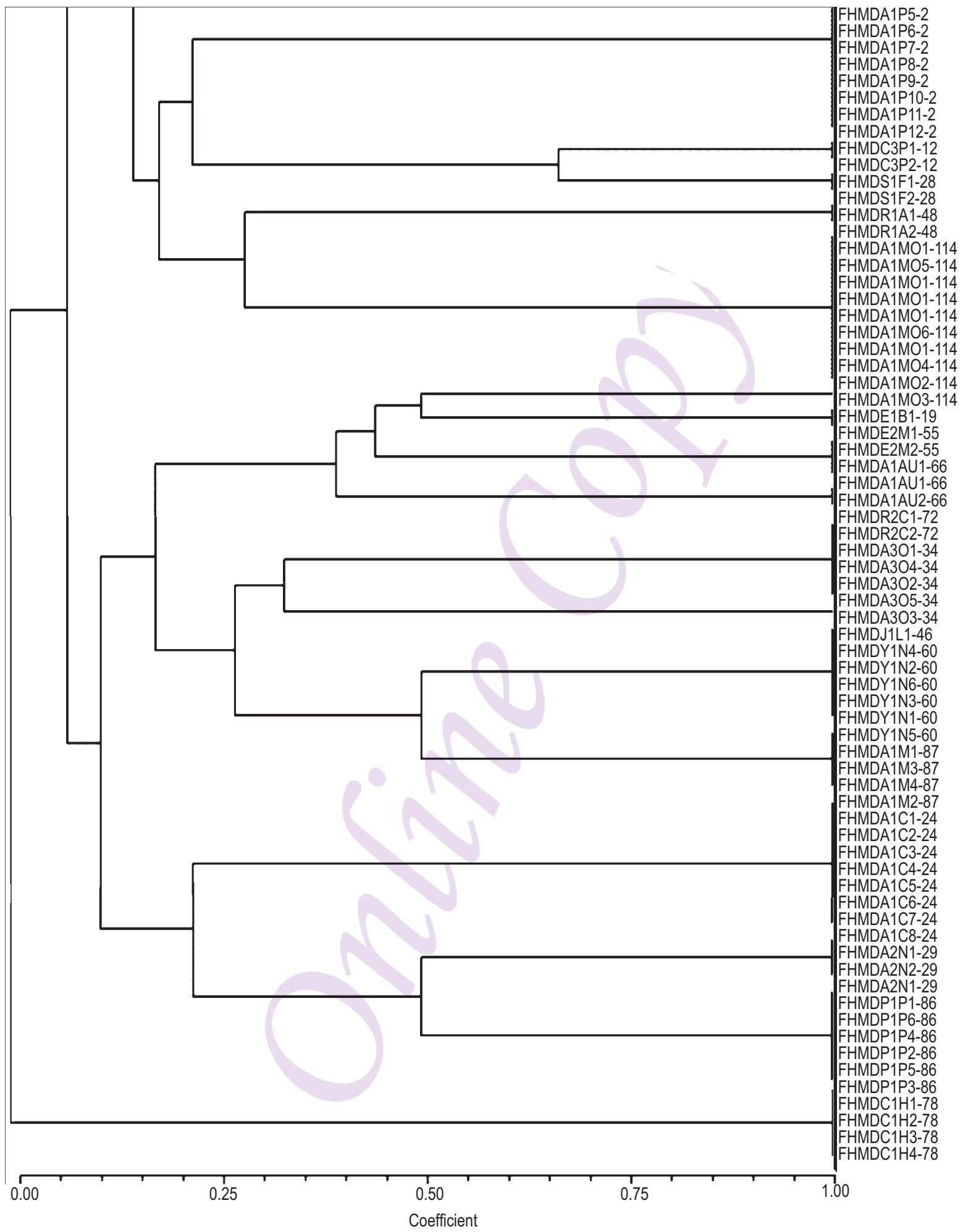

Fig. 1: Dendrogram constructed from the ARDRA patterns and distance matrix calculated by the UPGMA method using NTSYSPC 2.02e. ARDRA band patterns were obtained by digestion of the amplified $16 \mathrm{~S}$ rDNAgene with Haelll endonuclease 


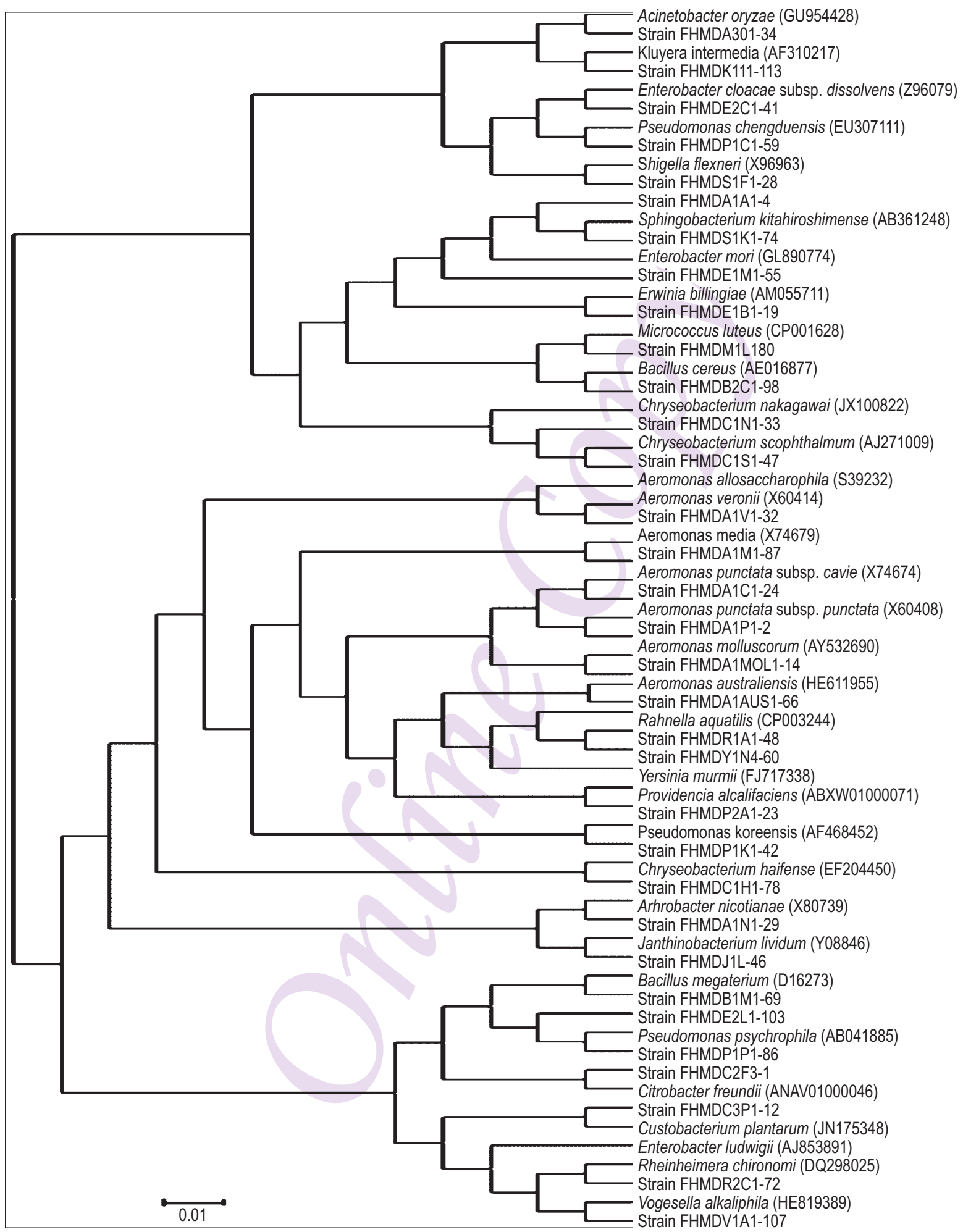

Fig. 2 : Phylogenetic relationship of $16 \mathrm{~S}$ rDNA sequences $(n=33)$ to show their relationship with their nearest relative taxon selected from Ez-Taxon database. Tree was constructed by using neighbor-joining analysis based on $16 \mathrm{~S}$ rDNA sequences 
Supplementary Table 1: Biochemical tests of representative bacterial strains isolated from a wetland of Lakhimpur-Kheri, U.P., India

\begin{tabular}{|c|c|c|c|c|c|c|c|c|c|c|c|c|c|c|c|c|c|}
\hline Biochemical tests & 1 & 2 & 3 & 4 & 5 & 6 & 7 & 8 & 9 & 10 & 11 & 12 & 13 & 14 & 15 & 16 & \\
\hline Gram staining & - & - & - & - & - & - & - & - & + & - & - & - & - & - & - & - & \\
\hline Shape & Rod & Rod & Rod & Rod & Rod & Rod & Rod & Rod & Rod & Rod & Rod & Rod & Rod & Rod & Rod & Rod & \\
\hline Motility & + & + & + & + & - & - & + & - & + & + & - & - & + & + & - & - & \\
\hline Oxidase & + & + & + & - & - & - & + & - & - & + & - & - & - & + & - & + & \\
\hline Catalase & + & + & + & + & + & + & + & + & + & + & - & + & + & + & + & + & \\
\hline ONPG & + & + & + & - & + & - & + & + & - & - & - & - & + & - & - & - & \\
\hline Lysine utilization & - & - & - & - & - & - & - & - & - & - & - & - & - & - & - & - & \\
\hline Ornithine utilization & - & - & - & - & - & - & - & - & - & - & - & - & - & - & - & - & \\
\hline Urease & - & - & - & - & - & - & - & - & - & - & - & - & - & - & - & - & \\
\hline Phenylalanine deamination & - & - & - & + & + & - & - & + & + & + & - & - & - & - & - & - & \\
\hline Nitrate reduction & + & + & + & + & + & + & + & + & - & + & - & - & + & - & - & + & \\
\hline $\mathrm{H}_{2} \mathrm{~S}$ production & + & - & - & - & - & - & - & - & - & - & - & - & - & - & - & - & \\
\hline Citrate utilization & + & - & - & - & - & - & + & - & - & + & - & + & + & + & - & - & \\
\hline Voges proskauer's & - & - & - & - & - & - & - & - & - & - & - & - & - & - & - & - & \\
\hline Methyl red & + & + & + & + & + & + & + & + & - & + & + & - & + & - & - & + & \\
\hline Indole & - & + & - & - & - & - & + & + & - & - & - & - & - & - & - & - & \\
\hline Malonate utilization & - & - & - & + & - & - & - & - & + & + & - & + & + & + & - & - & \\
\hline Esculin hydrolysis & - & + & + & + & + & - & + & - & - & - & + & - & + & - & + & + & \\
\hline Arabinose & + & + & - & + & + & - & + & + & - & + & - & - & + & + & + & - & \\
\hline Xylose & + & - & - & + & + & - & - & + & - & + & - & - & + & + & + & - & \\
\hline Adonitol & - & - & - & - & + & - & - & - & - & - & - & - & - & - & - & - & \\
\hline Rhamnose & - & - & - & + & + & - & - & + & - & - & - & - & - & - & - & - & \\
\hline Cellobiose & + & - & + & - & - & - & - & - & - & - & - & - & + & - & - & - & \\
\hline Melibiose & - & - & - & - & + & - & - & + & - & + & - & - & + & + & - & - & \\
\hline Saccharose & + & + & + & + & + & - & + & - & + & + & - & - & + & - & - & + & \\
\hline Raffinose & - & - & - & - & + & - & - & - & - & - & - & - & + & - & - & - & \\
\hline Trehalose & + & + & + & + & + & - & + & + & - & + & - & - & + & - & - & - & \\
\hline Glucose & + & + & + & + & + & - & + & + & + & + & - & - & + & + & - & + & \\
\hline Lactose & - & + & + & - & + & - & + & + & - & - & - & - & - & - & - & - & \\
\hline Biochemical tests & 17 & 18 & 19 & 20 & 21 & 22 & 23 & 24 & 25 & 26 & 27 & 28 & 29 & 30 & 31 & 32 & 33 \\
\hline Gram staining & - & - & - & - & - & + & - & - & - & + & - & - & + & - & - & - & - \\
\hline Shape & Rod & Rod & Rod & Rod & Rod & Rod & Rod & Rod & Rod & cocii & Rod & Rod & Rod & Rod & Rod & Rod & Rod \\
\hline Motility & - & - & + & + & + & + & + & - & - & - & + & + & - & + & - & + & + \\
\hline Oxidase & - & + & - & - & + & - & + & + & + & - & + & + & + & - & + & + & + \\
\hline Catalase & + & - & + & + & + & + & - & + & + & + & + & + & + & + & + & + & + \\
\hline ONPG & + & + & + & + & + & + & - & - & - & - & - & - & - & - & - & + & - \\
\hline Lysine utilization & - & - & - & - & - & - & - & - & - & - & - & - & - & - & + & - & - \\
\hline Ornithine utilization & - & - & - & - & - & - & - & - & - & - & - & - & - & - & + & - & - \\
\hline Urease & - & - & - & 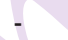 & - & - & - & - & - & - & - & - & - & - & - & - & - \\
\hline Phenylalanine deamination & - & - & - & - & - & - & - & - & - & - & - & + & - & - & - & - & + \\
\hline Nitrate reduction & - & + & + & + & + & + & + & - & + & - & - & + & + & + & + & + & + \\
\hline $\mathrm{H}_{2} \mathrm{~S}$ production & - & - & - & - & - & - & - & - & - & - & - & - & - & - & - & - & - \\
\hline Citrate utilization & + & + & + & + & + & + & - & + & - & + & - & + & - & + & + & + & - \\
\hline Voges proskauer's & - & - & - & - & - & - & - & - & - & - & - & - & - & - & - & - & - \\
\hline Methyl red & - & + & + & + & - & - & - & - & + & - & + & + & + & - & - & - & - \\
\hline Indole & - & - & - & - & - & - & - & - & - & - & - & - & - & - & - & + & - \\
\hline Malonate utilization & - & - & + & - & - & - & - & - & - & - & - & + & - & - & - & + & - \\
\hline Esculin hydrolysis & + & + & + & + & + & + & - & + & + & - & - & - & + & - & - & - & - \\
\hline Arabinose & + & + & + & + & + & + & - & - & - & + & - & + & - & + & + & + & + \\
\hline Xylose & + & + & + & + & - & + & - & - & - & + & - & + & - & + & + & - & - \\
\hline Adonitol & + & - & - & + & - & - & - & - & - & - & - & - & - & - & - & + & - \\
\hline Rhamnose & + & + & - & + & - & + & - & - & - & - & - & - & - & - & - & + & - \\
\hline Cellobiose & - & + & - & + & - & - & + & - & - & + & + & - & - & + & - & - & + \\
\hline Melibiose & - & + & - & + & - & - & + & - & - & + & + & + & - & + & - & + & - \\
\hline
\end{tabular}


Saccharose

Raffinose

Trehalose

Glucose

Lactose

$\begin{array}{lllllllllllllllll}- & - & - & - & + & - & - & - & + & - & - & + & + & + & + & + & + \\ - & - & - & + & - & - & - & - & + & - & - & - & + & + & + & + & - \\ + & + & + & + & + & + & - & - & - & - & - & + & - & + & - & + & + \\ + & + & + & + & + & + & - & + & + & - & + & + & + & + & + & + & + \\ - & - & - & + & - & - & - & - & - & - & - & - & - & - & - & - & -\end{array}$

1: C. freundii, 2: A. punctata subsp. punctata, 3: A. allosaccharophila, 4: C. plantarum, 5: E. billingiae, 6: P. alcalifaciens, 7: A. punctata subsp. caviae, 8: S. flexneri, 9: A. nicotianae, 10: A. veronii, 11: C. nakagawai, 12: A. oryzae, 13: E. cloacae subsp. dissolvens, 14: P. koreensis, 15: J. lividum, 16: C. scophthalmum, 17: R. aquatilis, 18: E. mori, 19: P. chengduensis, 20: Y. nurmii, 21: A. australiensis, 22: B. megaterium, 23: R. chironomi, 24: S. kitahiroshimense, 25: C. haifense, 26: M. luteus, 27: P. psychrophila, 28: A. media, 29: B. cereus, 30: E. ludwigii, 31: V. alkaliphila, 32: K. intermedia, 33: A. molluscorum

Table 2 : Antibiotic sensitivity test of the bacterial isolates from a wetland of Lakhimpur-Kheri, U.P., India

\begin{tabular}{|c|c|c|c|c|c|c|c|c|c|c|c|c|}
\hline Strain I.D. & 1 & 2 & 3 & 4 & 5 & 6 & 7 & 8 & 9 & 10 & 11 & 12 \\
\hline Citrobacterfreundii & $\mathrm{R}$ & $10^{R}$ & $25^{\mathrm{s}}$ & $10^{R}$ & $15^{\mathrm{s}}$ & $15^{\prime}$ & $8^{R}$ & $\mathrm{R}$ & $\mathrm{R}$ & $R$ & $\mathrm{R}$ & $8^{R}$ \\
\hline Aeromonas punctata subsp. punctata & $\mathrm{R}$ & $20^{5}$ & $35^{\mathrm{s}}$ & $15^{\mathrm{s}}$ & $22^{s}$ & $23^{\mathrm{s}}$ & $25^{5}$ & $30^{5}$ & $\mathrm{R}$ & $25^{5}$ & $20^{\prime}$ & $12^{5}$ \\
\hline Aeromonas allosaccharophila & $\mathrm{R}$ & $15^{\mathrm{s}}$ & $20^{5}$ & $15^{\mathrm{s}}$ & $15^{\mathrm{s}}$ & $15^{1}$ & $20^{\mathrm{S}}$ & $15^{1}$ & $15^{1}$ & $15^{1}$ & $15^{1}$ & $15 S$ \\
\hline Curtobacterium plantarum & $15^{s}$ & $15^{s}$ & $20^{5}$ & $15^{\mathrm{s}}$ & $15^{\mathrm{s}}$ & $15^{\prime}$ & $15 S$ & $15^{1}$ & $15^{1}$ & $15^{1}$ & $15^{\prime}$ & $10^{R}$ \\
\hline Erwinia billingiae & $\mathrm{R}$ & $20^{5}$ & $35^{\mathrm{s}}$ & $18^{\mathrm{s}}$ & $25^{\mathrm{s}}$ & $25^{\mathrm{s}}$ & $30^{5}$ & $30^{5}$ & $30^{5}$ & $30^{5}$ & $15^{1}$ & $12^{5}$ \\
\hline Providencia alcalifaciens & $\mathrm{R}$ & $15^{\mathrm{s}}$ & $20^{5}$ & $15^{\mathrm{s}}$ & $15^{\mathrm{s}}$ & $15^{1}$ & $15^{\mathrm{s}}$ & $15^{\prime}$ & $15^{1}$ & $15^{1}$ & $10^{R}$ & $10^{R}$ \\
\hline Aeromonas punctata subsp. caviae & $\mathrm{R}$ & $15^{5}$ & $20^{5}$ & $15^{\mathrm{s}}$ & $15^{\mathrm{s}}$ & $20^{5}$ & $15^{\mathrm{s}}$ & $15^{1}$ & 15 & 15 & $\mathrm{R}$ & $10^{R}$ \\
\hline Shigella flexneri & $\mathrm{R}$ & $13^{\prime}$ & $\mathrm{R}$ & $12^{R}$ & $14^{\prime}$ & $13^{R}$ & $8^{R}$ & $15^{1}$ & $11^{R}$ & $\mathrm{R}$ & $8^{R}$ & $8^{R}$ \\
\hline Arthrobacternicotianae & $20^{5}$ & $15^{\mathrm{s}}$ & $25^{\mathrm{s}}$ & $15^{5}$ & $15^{\mathrm{s}}$ & $15^{1}$ & $20^{\mathrm{S}}$ & $15^{1}$ & $15^{1}$ & $15^{1}$ & 15 & $10^{R}$ \\
\hline Aeromonas veronii & $\mathrm{R}$ & $15^{5}$ & $33^{\mathrm{s}}$ & $25^{\mathrm{s}}$ & $20^{5}$ & $25^{\mathrm{s}}$ & $30^{\mathrm{S}}$ & $30^{5}$ & $30^{5}$ & $30^{5}$ & $\mathrm{R}$ & $8^{R}$ \\
\hline Chryseobacterium nakagawai & $\mathrm{R}$ & $\mathrm{R}$ & $20^{5}$ & $\mathrm{R}$ & $\mathrm{R}$ & $\mathrm{R}$ & $15^{\mathrm{s}}$ & $10^{R}$ & $20^{5}$ & $20^{5}$ & $10^{R}$ & $R$ \\
\hline Acinetobacter oryzae & $\mathrm{R}$ & $15^{\mathrm{s}}$ & $20^{5}$ & $15^{\mathrm{s}}$ & $20^{5}$ & $20^{5}$ & $25^{5}$ & $15^{\prime}$ & $25^{\mathrm{s}}$ & $20^{5}$ & $15^{1}$ & $12^{5}$ \\
\hline Enterobacter cloacae subsp. dissolvens & $\mathrm{R}$ & $13^{\prime}$ & $25^{\mathrm{s}}$ & $15^{\mathrm{s}}$ & $15^{\mathrm{s}}$ & $15^{1}$ & $17^{\mathrm{s}}$ & $\mathrm{R}$ & $20^{\mathrm{S}}$ & $20^{5}$ & $\mathrm{R}$ & $\mathrm{R}$ \\
\hline Pseudomonas koreensis & $\mathrm{R}$ & $15^{5}$ & $20^{5}$ & $15^{\mathrm{s}}$ & $15^{\mathrm{s}}$ & $20^{\mathrm{s}}$ & $20^{\mathrm{S}}$ & $15^{1}$ & $25^{\mathrm{s}}$ & $28^{5}$ & $\mathrm{R}$ & $15^{\mathrm{s}}$ \\
\hline Janthinobacterium lividum & $\mathrm{R}$ & $20^{5}$ & $25^{\mathrm{s}}$ & $20^{5}$ & $30^{5}$ & $25^{\mathrm{s}}$ & $30^{\mathrm{s}}$ & $18^{\mathrm{S}}$ & $30^{\mathrm{S}}$ & $30^{5}$ & $15^{1}$ & $12^{5}$ \\
\hline Chryseobacterium scophthalmum & $\mathrm{R}$ & $15^{s}$ & $50^{s}$ & $\mathrm{R}$ & $20^{5}$ & $\mathrm{R}$ & $30^{5}$ & $20^{5}$ & $50^{\mathrm{s}}$ & $30^{5}$ & $12^{R}$ & $12^{5}$ \\
\hline Rahnella aquatilis & $\mathrm{R}$ & $20^{5}$ & $35^{s}$ & $15^{\mathrm{s}}$ & $30^{5}$ & $25^{\mathrm{s}}$ & $30^{5}$ & $30^{\mathrm{s}}$ & $30^{5}$ & $30^{5}$ & $20^{\prime}$ & $12^{s}$ \\
\hline Enterobactermori & $\mathrm{R}$ & $15^{s}$ & $30^{5}$ & $15^{\mathrm{s}}$ & $20^{\mathrm{s}}$ & $20^{5}$ & $16^{\mathrm{s}}$ & $16^{\prime}$ & $20^{\mathrm{s}}$ & $20^{5}$ & $14^{\prime}$ & $8^{R}$ \\
\hline Pseudomonas chengduensis & $\mathrm{R}$ & $15^{5}$ & $20^{5}$ & $15^{\mathrm{s}}$ & $15^{\mathrm{s}}$ & $20^{5}$ & $15^{\mathrm{s}}$ & $\mathrm{R}$ & $20^{5}$ & $20^{5}$ & $\mathrm{R}$ & $15^{\mathrm{s}}$ \\
\hline Yersinia nurmii & $\mathrm{R}$ & $15^{5}$ & $15^{1}$ & $15^{\mathrm{s}}$ & $15^{\mathrm{s}}$ & $15^{\prime}$ & $20^{\mathrm{S}}$ & $20^{\mathrm{S}}$ & $20^{\mathrm{S}}$ & $20^{5}$ & $20^{\prime}$ & $15^{\mathrm{s}}$ \\
\hline Aeromonas australiensis & $\mathrm{R}$ & $15^{s}$ & $20^{5}$ & $15^{\mathrm{s}}$ & $15^{\mathrm{s}}$ & $15^{1}$ & $15^{\mathrm{s}}$ & $15^{1}$ & $20^{\mathrm{s}}$ & $20^{5}$ & $10^{R}$ & $10^{R}$ \\
\hline Bacillus megaterium & $\mathrm{R}$ & $20^{\mathrm{s}}$ & $20^{5}$ & $20^{5}$ & $20^{5}$ & $20^{5}$ & $20^{\mathrm{s}}$ & $15^{1}$ & $20^{\mathrm{S}}$ & $20^{5}$ & $R$ & $15^{\mathrm{s}}$ \\
\hline Rheinheimera chironomi & $\mathrm{R}$ & $20^{5}$ & $25^{\mathrm{s}}$ & $20^{5}$ & $20^{5}$ & $20^{\mathrm{s}}$ & $20^{5}$ & $20^{\mathrm{S}}$ & $20^{\mathrm{S}}$ & $20^{5}$ & $20^{\prime}$ & $\mathrm{R}$ \\
\hline Sphingobacterium kitahiroshimense & $\mathrm{R}$ & $15^{5}$ & $30^{5}$ & $15^{\mathrm{s}}$ & $20^{5}$ & $20^{\mathrm{s}}$ & $16^{\mathrm{s}}$ & $16^{\prime}$ & $20^{\mathrm{S}}$ & $20^{5}$ & $14^{1}$ & $8^{R}$ \\
\hline Chryseobacterium haifense & $\mathrm{R}$ & $15^{s}$ & $50^{5}$ & $\mathrm{R}$ & $20^{5}$ & $\mathrm{R}$ & $30^{5}$ & $20^{5}$ & $50^{\mathrm{s}}$ & $30^{5}$ & $12^{R}$ & $112^{5}$ \\
\hline Micrococcus luteus & $25^{5}$ & $20^{5}$ & $20^{5}$ & $10^{R}$ & $15^{\mathrm{s}}$ & 15 & $25^{\mathrm{S}}$ & $25^{\mathrm{S}}$ & $20^{\mathrm{S}}$ & $15^{1}$ & $10^{R}$ & $5^{R}$ \\
\hline Pseudomonas psychrophila & $\mathrm{R}$ & $10^{R}$ & $20^{5}$ & $15^{5}$ & $10^{R}$ & 15 & $20^{5}$ & $10^{R}$ & $15^{1}$ & 15 & $10^{R}$ & $5^{R}$ \\
\hline Aeromonas media & $\mathrm{R}$ & $15^{5}$ & $33^{5}$ & $25^{s}$ & $20^{5}$ & $25^{\mathrm{s}}$ & $30^{\mathrm{s}}$ & $30^{5}$ & $30^{\mathrm{s}}$ & $30^{5}$ & $R$ & $8^{R}$ \\
\hline Bacillus cereus & $\mathrm{R}$ & $15^{5}$ & $15^{1}$ & $15^{\mathrm{s}}$ & $15^{\mathrm{s}}$ & 15 & $20^{5}$ & $20^{5}$ & $20^{5}$ & $20^{5}$ & $20^{1}$ & $15^{5}$ \\
\hline Enterobacterludwigii & $\mathrm{R}$ & $10^{R}$ & $20^{5}$ & $10^{R}$ & $15^{\mathrm{s}}$ & $15^{\prime}$ & $17^{\mathrm{s}}$ & 15 & $15^{1}$ & 15 & $10^{R}$ & $10^{R}$ \\
\hline Vogesella alkaliphila & $\mathrm{R}$ & $20^{5}$ & $22^{\mathrm{s}}$ & $15^{\mathrm{s}}$ & $15^{5}$ & $20^{5}$ & $18^{\mathrm{S}}$ & $20^{5}$ & $20^{5}$ & $18^{5}$ & 20 & $15^{\mathrm{s}}$ \\
\hline Kluyvera intermedia & $\mathrm{R}$ & $5^{R}$ & $20^{5}$ & $10^{R}$ & $20^{5}$ & $10^{R}$ & $15^{\mathrm{s}}$ & $20^{\mathrm{S}}$ & $20^{5}$ & $20^{5}$ & $\mathrm{R}$ & $\mathrm{R}$ \\
\hline Aeromonas molluscorum & $\mathrm{R}$ & $10^{R}$ & $20^{5}$ & $10^{R}$ & $15^{\mathrm{S}}$ & $15^{1}$ & $20^{5}$ & $20^{5}$ & $20^{5}$ & $\sqrt{15}$ & $20^{\prime}$ & $5^{R}$ \\
\hline
\end{tabular}

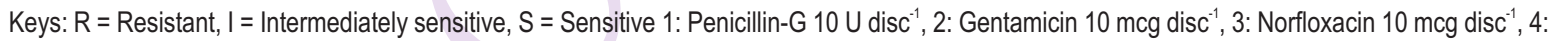

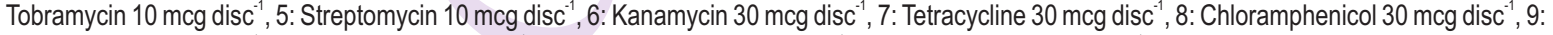

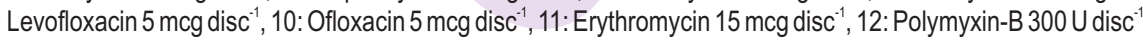

Levofloxacin, Ofloxacin, Erythromycin and Polymyxin-B. Overnight grown bacterial suspension was spread on MuellerHinton Agar and each antimicrobial agent (antibiotic disc) was placed uniformly on medium and incubated at $25^{\circ} \mathrm{C}$. The clearance zone for each isolate was recorded after $24 \mathrm{hr}$ of incubation. The isolates were classified as sensitive, intermediately sensitive and resistant according to the zone diameter (NCCLS, 2002). For all the isolates, the multiple antibiotic resistance (MAR) index values (a/b, where a represents the number of antibiotics the isolate was resistant to and $b$ 


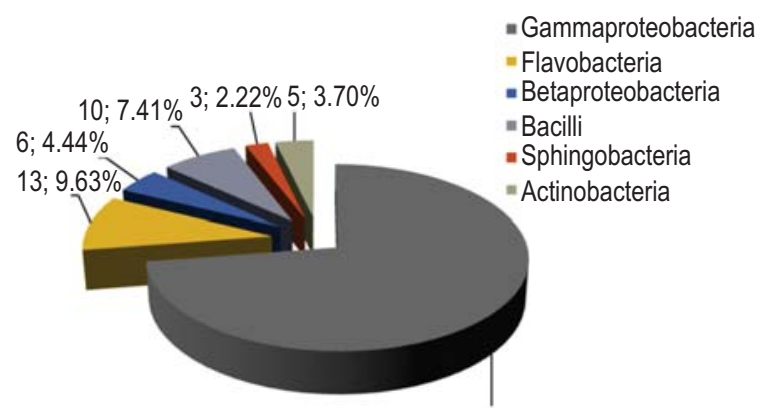

$98 ; 72.59 \%$

Fig. 3: Distribution of taxonomical classes of bacteria isolated from a wetland of Lakhimpur-Kheri, U.P., India

represents the total number of antibiotics the isolate was tested against) were calculated (Krumperman, 1983).

\section{Results and Discussion}

The present study was undertaken during winter season when the physico-chemical parameters viz., temperature, $\mathrm{pH}$ and dissolved oxygen of the water body were $14 \pm 1.8^{\circ} \mathrm{C}, 7.4 \pm 0.2$ and $5.68 \pm 0.54 \mathrm{ppm}$, respectively. In the present study, a total of 135 bacterial strains were isolated by the standard agar plating method (Table 1). From the total isolates, 33 single member phylotypes were produced by ARDRA, using Haelll endonuclease (Fig. 1) and also characterized biochemically (Supplementary Table 1). All the phylotypes were subjected to 16S rDNA sequencing and the above sequences were examined for similarity with reference sequences available in Ez-Taxon server, to establish their genotypic identification. Similarity between selected reference strains and the phylotypes ranged from $97.32-100 \%$, and these sequences were taken for phylogenetic analysis (Fig. 2).

Amplified rDNA restriction and confirmation analysis was used for the analysis of mixed bacterial population from different environments (Martínez-Murcia et al., 1995). Similarly, the $16 S$ rDNA sequencing is considered to provide unambiguous data for isolates and is reported to yield results, which are reproducible (Drancourt et al., 2000). The above molecular techniques helped in assigning bacterial isolates to 33 species belonging to 20 genera in 6 different classes namely, Gammaproteobacteria, Betaproteobacteria, Flavobacteria, Bacilli, Actinobacteria and Sphingobacteria. Majority of bacterial isolates belonged to class Gammaproteobacteria $(72.59 \%$; 98/135) followed by Flavobacteria (9.63\%; 13/135), Bacilli (7.41\%; 10/135), Betaproteobacteria (4.44\%; 6/135), Actinobacteria (3.70\%; $5 / 135)$ and Sphingobacteria (2.22\%; 3/135) (Fig. 3). In the present study, out of one hundred thirty five isolates, Aeromonas spp. were predominant $(35.55 \% ; 48 / 135)$ and included $A$. punctata subsp. punctata $(8.89 \% ; 12 / 135)$, A. punctata subsp. caviae $(5.93 \% ; 8 / 135), A$. veronii $(4.44 \% ; 6 / 135), A$. allosaccharophila $(3.70 \% ; 5 / 135), \quad$ A. australiensis $(2.22 \%$; $3 / 135)$, A. media $(2.96 \% ; 4 / 135)$ and $A$. molluscorum $(7.41 \%$; 10/135). In addition, three species of Chryseobacterium spp. viz. C. nakagawai $(5.19 \% ; 7 / 135)$; C. haifense $(2.96 \% ; 4 / 135)$; C. scophthalmum $(1.48 \% ; 2 / 135)$ and two species of Bacillus viz. $B$. megaterium $(4.44 \% ; 6 / 135)$ and $B$. cereus $(2.96 \% ; 4 / 135)$ were also recorded. In a previous study, 203 bacterial strains isolated from freshwater of Woopo wetland were grouped under 39 single member phylotypes using Haelll endonuclease in ARDRA (Baik et al., 2008). Similarly, 43 different bacterial species isolated from Gangetic river in Uttarakhand were grouped in 24 genera on the

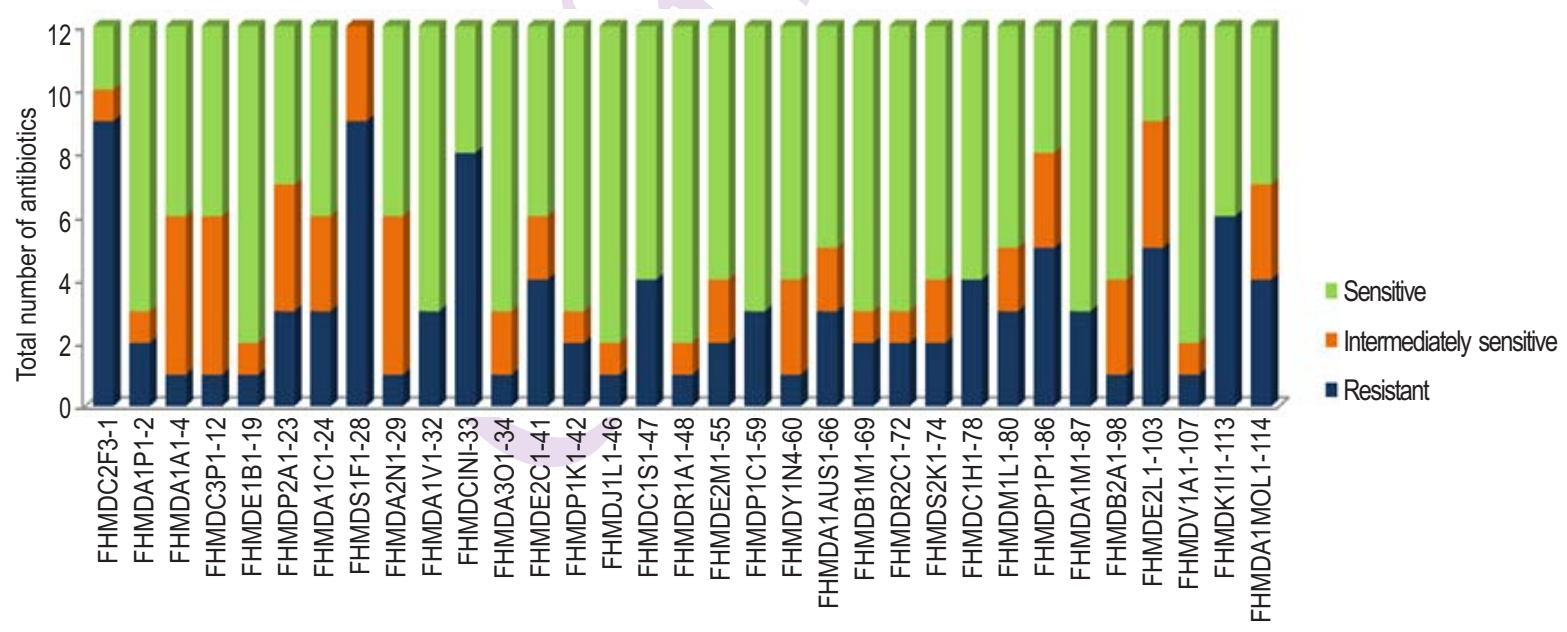

Bacterial strains

Fig. 4 : Antibiotic sensitivity test of bacterial strains isolated from a wetland of Lakhimpur-Kheri, U.P., India. 
Table 3 : Multiple antibiotic resistance pattern of bacterial phylotypes of a wetland of Lakhimpur-Kheri, U.P., India

\begin{tabular}{|c|c|c|c|c|c|}
\hline \multirow[t]{2}{*}{ Strain } & \multirow{2}{*}{$\begin{array}{l}\text { Percentage }(\%) \text { composition } \\
\text { of bacteria }\end{array}$} & \multicolumn{3}{|c|}{ Sensitivity to antibiotics } & \multirow[t]{2}{*}{ MAR index } \\
\hline & & & 1 & S & \\
\hline Citrobacter freundii & 3.70 & 75 & 8.33 & 16.67 & 0.75 \\
\hline Aeromonas punctata subsp. punctata & 8.89 & 16.67 & 8.33 & 75 & 0.17 \\
\hline Aeromonas allosaccharophila & 3.70 & 8.33 & 41.67 & 50 & 0.08 \\
\hline Curtobacterium plantarum & 1.48 & 8.33 & 41.67 & 50 & 0.08 \\
\hline Erwinia billingiae & 0.74 & 8.33 & 8.33 & 83.34 & 0.08 \\
\hline Providencia alcalifaciens & 1.48 & 25 & 33.33 & 41.67 & 0.25 \\
\hline Aeromonas punctata subsp. caviae & 5.93 & 25 & 25 & 50 & 0.25 \\
\hline Shigella flexneri & 1.48 & 75 & 25 & 0 & 0.75 \\
\hline Arthrobacternicotianae & 2.22 & 8.33 & 41.67 & 50 & 0.08 \\
\hline Aeromonas veronii & 4.44 & 25 & 0 & 75 & 0.25 \\
\hline Chryseobacterium nakagawai & 5.19 & 66.67 & 0 & 33.33 & 0.67 \\
\hline Acinetobacteroryzae & 3.70 & 8.33 & 16.67 & 75 & 0.08 \\
\hline Enterobacter cloacae subsp. dissolvens & 2.96 & 33.33 & 16.67 & 50 & 0.33 \\
\hline Pseudomonas koreensis & 3.70 & 16.67 & 8.33 & 75 & 0.17 \\
\hline Janthinobacterium lividum & 0.74 & 8.33 & 8.33 & 83.34 & 0.08 \\
\hline Chryseobacterium scophthalmum & 1.48 & 33.33 & 0 & 66.67 & 0.33 \\
\hline Rahnella aquatilis & 1.48 & 8.33 & 8.33 & 83.34 & 0.08 \\
\hline Enterobactermori & 1.48 & 16.67 & 8.33 & 75 & 0.17 \\
\hline Pseudomonas chengduensis & 2.22 & 25 & 0 & 75 & 0.25 \\
\hline Yersinia nurmii & 4.44 & 8.33 & 25 & 66.67 & 0.08 \\
\hline Aeromonas australiensis & 2.22 & 25 & 8.33 & 66.67 & 0.25 \\
\hline Bacillus megaterium & 4.44 & 16.67 & 8.33 & 75 & 0.17 \\
\hline Rheinheimera chironomi & 1.48 & 16.67 & 8.33 & 75 & 0.17 \\
\hline Sphingobacterium kitahiroshimense & 2.22 & 16.67 & 16.67 & 66.66 & 0.17 \\
\hline Chryseobacterium haifense & 2.96 & 33.33 & 0 & 66.67 & 0.33 \\
\hline Micrococcus luteus & 1.48 & 25 & 16.67 & 58.33 & 0.25 \\
\hline Pseudomonas psychrophila & 4.44 & 50 & 25 & 25 & 0.50 \\
\hline Aeromonasmedia & 2.96 & 25 & 0 & 75 & 0.25 \\
\hline Bacillus cereus & 2.96 & 8.33 & 25 & 66.67 & 0.08 \\
\hline Enterobacterludwigii & 0.74 & 41.67 & 33.33 & 25 & 0.42 \\
\hline Vogesella alkaliphila & 3.70 & 8.33 & 8.33 & 83.34 & 0.08 \\
\hline Kluyvera intermedia & 1.48 & 50 & 0 & 50 & 0.50 \\
\hline Aeromonas molluscorum & 7.41 & 33.33 & 25 & 41.67 & 0.33 \\
\hline
\end{tabular}

basis of 16S rDNA sequencing (Sood et al., 2010). In the present study, bacterial diversity analysis indicated dominance of Gram negative bacteria. The abundance of Gram negative bacteria at different sites may be attributed to increased addition of the excretory substances to the water. In addition, few Gram positive bacteria were also isolated in the present study and this is in agreement with findings of Torimiro et al. (2014) who also reported Gram negative, as well as Gram positive bacteria in fish pond water.

The bacterial diversity analysis of wetland also indicated bacterial population of aquatic, soil, animal and plant origin. As it is well known that microorganisms are widely distributed in nature, they can be transported to the wetland system through the rains, mainly with the particulate matter. In the present study, four bacterial species of plant origin viz. C. plantarum, E. billingiae, Enterobacter mori and $A$. oryzae were also identified. It can be assumed that the bacterial isolates related to plant habitat might have been contributed by the native plant inhabitants. Similar to the present results, Baik et al. (2008) reported that bacterial community in the wetland has a relationship with plant and animal inhabitants. Presence of bacteria of animal and plant origin is also considered as a property of freshwater pond ecological niche (Baik et al., 2008). Interestingly, in the present study, four species of bacteria viz. Sphingobacterium kitahiroshimense, Yersinia nurmii, Pseudomonas koreensis, and Vogesella alkaliphila are first report from freshwater habitat. Earlier, these four species have been reported from broiler meat, Yersinia nurmii (MurrosKontiainen et al., 2011), soil, Vogesella alkaliphila (Subhash et al., 2013), soil, Sphingobacterium kitahiroshimense (Matsuyama et al., 2008), soil, Pseudomonas koreensis (Kwon et al., 2003). In addition, some of the bacterial isolates belonging to class Proteobacteria (Alpha and Beta-proteobacteria), Bacteriodetes, and Actinobacteria were also isolated, which are restricted to only freshwater ecosystems and thus, represent native organisms (Newton et al., 2011; Huang et al., 2013). Some of the bacterial 
species isolated in the present study have been associated with fish diseases viz., C. freundii (Karunasagar et al., 1992), Aeromonas spp. (Janda and Abbott, 2010), E. cloacae (Sekar et al., 2008) and P. koreensis (Shahi and Mallik, 2014).

All the identified phylotypes (33) were examined for their sensitivity to 12 antibiotics. The numerical sensitivity profiles are given in Table 2 and Fig. 4 . The in-vitro antibiotic sensitivity test revealed great variation in sensitivity of the bacterial isolates from freshwater source. The bacterial isolates viz. Erwinia billingiae, Janthomonas lividum, R. aquatilis and V. alkaliphila were sensitive to maximum number of antibiotics (83.34\%; 10/12). On the contrary, aeromonads viz. A. punctata subsp. punctata, $A$. veronii and $A$. media were sensitive against minimum number of antibiotics $(25 \%$; $3 / 12)$ followed by $A$. australiensis $(33.33 \%$; 4/12), A. allosaccharophila, A. punctata subsp. caviae (50\%; $6 / 12$ ) and $A$. molluscorum $(58.33 \% ; 7 / 12)$.

The isolates from different genera also showed variable range of resistance pattern to different antibiotics (Table 3). Citrobacter freundii showed resistance to maximum numbers of antibiotics (75\%; 9/12) followed by C. nakagawai (66.67\%; 8/12) and Pseudomonas psychrophila (50\%; 6/12). Among the twelve antibiotics tested, maximum bacterial resistance was observed to Penicillin-G (90.9\%; 30/33) followed by Polymyxin-B (57.5\%; 19/33) and Erythromycin (54.5\%; 18/33), and minimum resistance was observed to Norfloxacin $(3.03 \% ; 1 / 33)$ followed by Ofloxacin $(6.06 \% ; 2 / 33)$ and Levofloxacin $(9.09 \% ; 3 / 33)$. Among the 33 representative isolates, $51.5 \%$ of the isolates (17/33) showed multiple antibiotic resistance (Fig.4 and Table 3). Multiple antibiotic resistance levels of some of the common bacterial species viz., Aeromonas, Chryseobacterium and Pseudomonas were $22.62 \%, 44.44 \%$ and $30.55 \%$, respectively. In addition, two important opportunistic bacteria C. freundii and Shigella flexneri were $100 \%$ resistant against nine antibiotics and the level of multiple resistance were $75 \%$ of each. The MAR index mean values for the isolates viz. Aeromonas, Pseudomonas, Chryseobacterium, C. freundii and S. flexneri were 0.226, 0.306, $0.443,0.75$ and 0.75 , respectively. The results of the present study on antibiotic resistance and multiple resistance are consistent with earlier reports of fish pathogens and bacteria in aquatic environments (Verner-Jeffreys et al., 2009; Matyar et al., 2010; Nguyen et al., 2014). Motile Aeromonas spp. and Pseudomonas spp., which are recognized as ubiquitous aquatic Gram-negative bacteria in freshwater environment have been reported to show high incidence of resistance rates of 25-30\% and $89-91 \%$, respectively (Nguyen et al., 2014). Since, these genera are reported to develop single or multiple antibiotic resistance readily (Akinbowale et al., 2007), it has been suggested to use these genera as indicators for antimicrobial resistance in the freshwater aquaculture environment (Petersen and Dalsgaard, 2003). Earlier, Sunder et al. (2006) reported that the phenomenon of even distribution of resistance in bacteria, may be due to common environment and exchange of genetic material. It is noteworthy that in the present study, we had selected the wetland where antibiotics are not used for aquaculture purposes. However, the MAR index mean values indicated that the wetland water can be a reservoir for multidrug resistance bacteria. Nonetheless, similar or higher values of MAR index were found in other reports and attributed mainly to aquaculture practices (Matyar et al., 2010; Nguyen et al., 2014). Hence from the present study, it can be assumed that the occurrence of antibiotic resistance and MAR among bacteria isolated from wetland could be due to flow of runoff from mainland. These results will help in strengthening our knowledge of bacterial ecology of the wetland ecosystem.

\section{Acknowledgments}

The authors are grateful to Dr. J.K. Jena, Director, National Bureau of Fish Genetic Resources and Coordinator, ICAR-National Surveillance Programme for Aquatic Animal Diseases (NSPAAD) for his encouragement and support. The financial support from National Fisheries Development Board for NSPAAD is gratefully acknowledged.

\section{References}

Akinbowale, O.L., H. Peng, P. Grant and M.D. Barton: Antibiotic and heavy metal resistance in motile aeromonads and pseudomonads from rainbow trout (Oncorhynchus mykiss) farms in Australia. Int. J.Antimicrob. Agents., 30, 177-182 (2007).

Angulo, F.J., V.N. Nargund and T.C. Chiller: Evidence of an association between use of antimicrobial agents in food animals and antimicrobial resistance among bacteria isolated from humans and the human health consequences of such resistance. J. Vet. Med. B., 51, 374-379 (2004).

Ash, R.J., B. Mauck and M. Morgan: Antibiotic resistance of Gramnegative bacteria in rivers, United States. Emerg. Infect. Dis., 8, 713-716 (2002).

Baik, K.S., S.C. Park, E.M. Kim, K.S. Bae, J.H. Ann, J.O. Ka, J. Chun and C.N. Seong: Diversity of bacterial community in freshwater of Woopo wetland. J. Microbiol., 46, 647-655 (2008).

Barton, M.D.: Antibiotic use in animals feed and its impact on human health. Nut. Res. Rev., 13, 79-299 (2000).

Bondad-Reantaso, M.G., R.P. Subasinghe, J.R. Arthur, K. Ogawa, S. Chinabut, R. Adlard, Z. Tan and M. Shariff: Disease and health management in Asian aquaculture. Vet. Parasitol., 132, 249-272 (2005).

Drancourt, M., C. Bollet, A. Carlioz, R. Martelin, J.P. Gayra and D. Raoult: 16S Ribosomal DNA Sequence Analysis of a large collection of environmental and clinical unidentifiable bacterial isolates. J. Clin. Microbiol., 38, 3623-3630 (2000).

Finegold, S.M. and W.J. Martin: Antimicrobial susceptibility tests and assays. In: Bailey and Scott's Diagnostic Microbiology (Eds.: W.R. Bailey, E.G. Scott, S.M. Finegold and W.J. Martin). The CV Mosby Company, St. Louis, Mo, USA. , pp. 385-404 (1982).

Huang, J.P., A.K. Swain, R.W. Thacker, R. Ravindra, D.T. Andersen and A.K. Bej: Bacterial diversity of the rock-water interface in an East Antarctic freshwater ecosystem, Lake Tawani (P). Aqu. Biosys., 9, (2013). (doi:10.1186/2046-9063-9-4). 
Janda, J.M. and S.L. Abbott: The Genus Aeromonas: Taxonomy, pathogenicity and infection. Clin. Microbiol. Rev., 23, 35-73 (2010).

Karunasagar, I., I.B. Karunasagar and R. Pai: Systemic Citrobacter freundii infection in common carp, Cyprinus carpio L., fingerlings. J. Fish Dis., 15, 95-98 (1992).

Kim, O.S., Y.J. Cho, K. Lee, S.H. Yoon, M. Kim, H. Na, S.C. Park, Y.S. Jeon, J.H. Lee, H. Yi, S. Won and J. Chun: Introducing EzTaxon: A prokaryotic 16S rRNA Gene sequence database with phylotypes that represent uncultured species. Int. J. Syst. Evol. Microbiol., 62, 716-721 (2012).

Krumperman, P.H.: Multiple antibiotic resistance indexing of Escherichia coli to identify high-risk sources of faecal contamination of foods. Appl. Environ. Microbiol., 46, 165-170 (1983).

Kwon, S.W., J.S. Kim, I.C. Park, S.H. Yoon, D.H. Park, C.K. Lim and S.J. Go: Pseudomonas koreensis sp. nov., Pseudomonas umsongensis sp. nov. and Pseudomonas jinjuensis sp. nov., novel species from farm soils in Korea. Int. J. Syst. Evol. Microbiol., 53, 21-27 (2003).

Lim, S.J., J. Eunhee, L. Sang-Hun, Y. Byeong-Hak, K. Sun-Kyoung and K. Tak-Hyun: Antibiotic resistance in bacteria isolated from freshwater aquacultures and prediction of the persistence and toxicity of antimicrobials in the aquatic environment. J. Environ. Sci. Hlth., Part B., 48, 495-504 (2013).

Martínez-Murcia, A.J., S.G. Acinas and F. Rodríguez-Valera: Evaluation of prokaryotic diversity by restrictase digestion of $16 \mathrm{~S}$ rDNA directly amplified from hipersaline environments. FEMS Microbiol. Ecol., 17, 247-256 (1995).

Matsuyama, H., H. Katoh, T. Ohkushi, A. Satoh, K. Kawahara and I. Yumoto: Sphingobacterium kitahiroshimense sp. nov., isolated from soil. Int. J. Sys. Evol. Microbiol., 58, 1576-1579 (2008).

Matyar, F., T. Akkan, Y. Uçak and B. Eraslan: Aeromonas and Pseudomonas: Antibiotic and heavy metal resistance species from Iskenderun Bay, Turkey (northeast Mediterranean Sea). Environ. Monit. Assess., 167, 309-320 (2010).

Murros-Kontiainen, A., M.F. Ahomaa, H. Korkeala, P. Johansson and J.R. Bjorkroth: Yersinia nurmii sp. nov. Int. J. Sys. Evol. Micro., 61, 2368-2372 (2011)

NCCLS: Performance standards for antimicrobial susceptibility testing. Twelfth informational supplement. NCCLS document M100-S12. NCCLS, Wayne, $\mathrm{Pa}$ (2002)

Newton, R.J., S.E. Jones, A. Eiler, K.D. McMahon and S. Bertilsson: A guide to the natural history of freshwater lake bacteria. Microbiol. Mol. Biol. Rev., 75, 14-49 (2011).

Nguyen, H.N.K., T.T.H. Van, H.T. Nguyen, P.M. Smooker, J. Shimeta and P.J. Coloe: Molecular characterization of antibiotic resistance in Pseudomonas and Aeromonas isolates from catfish of the Mekong Delta, Vietnam. Vet. Microbiol., 171, 397-405 (2014).

Petersen, A. and A. Dalsgaard: Species composition and antimicrobial resistance genes of Enterococcus spp., isolated from integrated and traditional fish farms in Thailand. Environ. Microbiol., 5, 395402 (2003).

Schmidt, A.S., M.S. Bruun, I. Dalsgaard, K. Pedersen and J.L. Larsen: Occurrence of antimicrobial resistance in Wsh-pathogenic and environmental bacteria associated with four Danish rainbow trout farms. Appl. Environ. Microbiol., 66, 4908-4915 (2000).

Sekar, V.T., T.C. Santiago, K.K. Vijayan, S.V. Alavandi, V.S. Raj, J.J.
Rajan, M. Sanjuktha and N. Kalaimani: Involvement of Enterobacter cloacae in the mortality of the fish, Mugil cephalus. Lett. Appl. Microbiol., 46, 667-672 (2008).

Shahi, N. and S.K. Mallik: Recovery of Pseudomonas koreensis from eye lesions in golden mahseer, Tor putitora (Hamilton, 1822) in Uttarakhand, India. J. Fish Dis., 37, 497-500 (2014).

Sood, A., P. Piyush, B. Sandeep, S. Shivesh, P.G. Manju and O.P. Gusain: Assessment of bacterial diversity in the Gangetic river system of Uttarakhand, India. Curr. Sci., 99, 1660-1663 (2010).

Stobberingh, E.E. and A.E. Van den Bogaard: Spread of antibiotic resistance from food animals to man. Acta Vet. Scand. Suppl., 93, 47-52 (2000).

Subhash, Y., L. Tushar, Ch. Sasikala and Ch. V. Ramana: Vogesella alkaliphila sp. nov., isolated from an alkaline soil and emended description of the genus Vogesella. Int. J. Syst. Evol. Microbiol., 63, 2338-2343 (2013).

Sunder, J., S. Jeyakumar, S.P.S. Ahlawat, R.B. Rai, A. Kundu, S. Senani, R.N. Chatterjee, S.K. Yadav and S. Saha: Antibiotic resistance pattern of bacterial isolates from fishes of Andaman and Nicobar Islands. Indian J. Fish., 53, 231-235 (2006).

Tamura, K., G. Stecher, D. Peterson, A. Filipski and S. Kumar: MEGA6: Molecular evolutionary Genetics Analysis Version 6.0. Mol. Biol. Evol., 30, 2725-2729 (2013).

Thompson, J.D., T.J. Gibson, F. Plewniak, F. Jeanmougin and D.G. Higgins: The CLUSTALX windows interface: Flexible strategies for multiple sequence alignment aided by quality analysis tools. Nucl. Acids Res., 25, 4876-4882 (1997).

Torimiro, N., P.T. Bebe, F.E. Ogundipe, D.M. Esan and A.I. Aduwo: The bacteriology and physico-chemical analysis of freshwater fish ponds. Int. Res. J. Microbiol., 5, 28-32 (2014).

Urakawa, H., K.K. Tsukamoto and K. Ohwada: Reassessment of the taxonomic position of Vibrio iliopiscarius (Onarheim et al., 1994) and proposal for Photobacterium iliopiscarium comb. nov. Int. J. Syst. Bacteriol., 49, 257-260 (1999).

Verner-Jeffreys, D.W., J.W. Timothy, S. Tamar, J.P. Michelle, J.W. Martin, J.H. Sarah, S.E.R. Georgina, R. Edward, M. Victoria and B.A. Craig: High prevalence of multidrug-tolerant bacteria and associated antimicrobial resistance genes isolated from ornamental fish and their carriage water. PLOS One., 4, 1-9 (2009).

Weisburg, W.G., S.M. Barns, D.A. Pelletier and D.J. Lane: 16 S ribosomal DNA amplification for phylogenetic study. J. Bacteriol., 173, 697-703 (1991).

Wilson, K.: Preparation of genomic DNA from bacteria. Miniprep of bacterial genomic DNA. In: Current protocols in molecular biology, (Eds.: F.M. Ausubel, R. Brent, R.E. Kingston, D.D. Moore, J.G. Seidman, J.A. Smith and K. Struhl). Greene Publishing Associates, Inc and John Wiley and Sons, Inc., New York, 1, pp. 241-245 (1994).

Yoon, Y.J., K.H. Im, Y.H. Koh, S.K. Kim and J.W. Kim: Genotyping of six pathogenic Vibrio species based on RFLP of $16 \mathrm{~S}$ rDNAs for rapid identification. J. Microbiol., 41, 312-319 (2003).

Zeng, Y., Y. Ma, C. Wei, N. Jiao, K. Tang, Z. Wu and Ji. Jian: Bacterial diversity in various coastal mariculture ponds in Southeast China and in diseased eels as revealed by culture and cultureindependent molecular techniques. Aqua. Res., 41, 172-186 (2010). 